\title{
Arterial Stiffness and Blood Pressure in Patients Newly Diagnosed with Graves' Disease Compared with Euthyroid Controls
}

\author{
Diana Grove-Laugesen ${ }^{a} \quad$ Sofie Malmstroem ${ }^{a} \quad$ Eva Ebbehoj $^{a} \quad$ Anne Lene Riis $^{b}$ \\ Torquil Watt $^{c}$ Lars Rejnmark ${ }^{a}$ Klavs Würgler Hansen ${ }^{d}$ \\ ${ }^{a}$ Department of Endocrinology and Internal Medicine, Aarhus University Hospital, Aarhus, Denmark; ${ }^{\mathrm{b}}$ Medical \\ Department, Regional Hospital Horsens, Horsens, Denmark; ' Department of Internal Medicine, Gentofte and Herlev \\ Hospital, Hellerup, Denmark; ${ }^{d}$ Medical Department, Silkeborg Regional Hospital, Silkeborg, Denmark
}

\section{Keywords}

Graves' disease - Arterial stiffness - Pulse wave analysis .

Blood pressure $\cdot$ Hyperthyroidism

\begin{abstract}
Introduction and Objective: The excess cardiovascular morbidity and mortality in hyperthyroidism and Graves' disease (GD) is inadequately understood. We aimed to elucidate whether well-established cardiovascular risk factors such as arterial stiffness in terms of pulse wave velocity (PWV) and blood pressure differ in GD and controls. Methods: This was a cross-sectional study comparing 55 hyperthyroid patients with newly diagnosed GD and 55 euthyroid, populationbased controls matched for age, sex and menopausal status. PWV and blood pressure were measured in office (SphygmoCor Xcel) and 24-h ambulatory settings (Arteriograph). Differences between groups were assessed using adjusted linear regression analysis. Results: Compared to controls, GD patients showed higher PWV in the 24-h but not in the office setting with an adjusted 24-h PWV difference of $1.0(95 \% \mathrm{Cl}$ : 0.6-1.5) $\mathrm{m} / \mathrm{s}$. PWV was higher in GD at both day and night, and nightly PWV dipping was lower $(-5.5,95 \% \mathrm{Cl}:-10.4$ to $-0.6 \%)$. Furthermore, central and brachial pulse pressure
\end{abstract}

was significantly higher in both the office and 24-h setting, whereas nightly central pulse pressure dipping was significantly lower in GD $(-5.4,95 \% \mathrm{Cl}$ : -10.5 to $-0.2 \%)$. Mean arterial pressure did not differ between the groups. Conclusions: Despite comparable blood pressure, GD is associated with a higher 24-h PWV that was not detected in the office setting. Pulse pressure was higher in GD, whereas mean arterial pressure did not differ between the groups. Longitudinal studies should pursue whether higher PWV might be a piece to the puzzle of understanding the increased risk of cardiovascular disease in hyperthyroidism and GD.

(c) 2020 European Thyroid Association Published by S. Karger AG, Basel

\section{Introduction}

Hyperthyroidism has been associated with a marked excess cardiovascular mortality in several observational studies [1-5]. In long-term follow-up, Graves' disease (GD) patients have a $23 \%$ excess risk of mortality and a $65 \%$ increased risk of acute myocardial infarction [5]. The mechanisms underlying these associations are incompletely understood. 
Arterial stiffness and blood pressure (BP) have been shown independently to predict cardiovascular morbidity and mortality and total mortality in both low- and high-risk populations [6-9]. The gold standard measurement of arterial stiffness is carotid-femoral pulse wave velocity (PWV) [10]. Only a few studies have been published on arterial stiffness in GD, and none of these assessed carotid-femoral PWV [11-17]. Increased arterial stiffness might provide a piece to the puzzle of the excess cardiovascular morbidity and mortality in GD. We aimed at investigating both office and ambulatory 24-h (24-h) PWV and BP in newly diagnosed GD patients compared to controls.

\section{Materials and Methods}

We recruited patients with newly diagnosed GD and population-based euthyroid controls matched for age ( \pm 2 years), sex and menopausal status. The patients with GD were all enrolled in a randomized controlled trial (the DAGMAR study) aiming to assess effects of vitamin D supplementation on the course of GD (Clinicaltrials.gov identifier NCT02384668). This trial is still ongoing. In the current paper, only data collected at baseline prior to the study intervention are reported. Recruitment and inclusion and exclusion criteria have previously been published $[18,19] . \mathrm{Pa}-$ tients were recruited from the outpatient clinics at Aarhus University Hospital and the Regional Hospitals of Central Denmark Region. The euthyroid controls were recruited from the background population by direct mailing to a random sample of the population in the referral regions of the hospitals, by bulletin in public places and by announcement on social media. Inclusion criteria of the patients were age between 18 and 80 years, a first-time diagnosis of GD, elevated level of thyrotropin receptor antibody, hyperthyroidism at first visit (TSH $<$ reference range and free levels of triiodothyronine and/or thyroxine $>$ reference range), and planned or initiated treatment with anti-thyroid drugs. Exclusion criteria for patients and controls were previous hyperthyroidism, hypercalcemia (ionized calcium above $1.40 \mathrm{mmol} / \mathrm{L}$ ), comorbidity as malignant or neuromuscular diseases or impaired renal function (estimated glomerular filtration rate (eGFR) $<45 \mathrm{~mL} / \mathrm{min}$ ), alcohol or drug abuse and inability to read and speak Danish. Participants were enrolled between March 2015 and July 2016.

\section{Equipment}

PWV, BP and pulse wave analysis were performed in the office setting and during ambulatory $24-\mathrm{h}$ monitoring. PWV is a measure of the speed of the pulse wave travelling through the aorta. Augmentation index (Aix) is a measure of the proportion of the central pulse pressure (PP) that is attributed to the reflected pulse wave. Office measurements were performed using the SphygmoCor Xcel device [20]. Twenty-four-hour monitoring was performed using the Arteriograph [21] (TensioMed Kft., Budapest, Hungary, www.tensiomed.com). Recordings were repeated every $20 \mathrm{~min}$ for $24 \mathrm{~h}$. Daytime and night-time were defined based on the participants' self-reported expected bedtime and rising hour.

Arterial Stiffness in Graves' Disease

\section{Measurement Procedures}

Office measurements were performed under standardized conditions in the morning. Simultaneous office measurements using the Arteriograph and the SphygmoCor Xcel were performed. Twenty-four-hour measurement required a minimum of 14 daytime and 7 night-time recordings of $\mathrm{BP}$ or $\mathrm{PWV}$, respectively, to be included in the analysis.

All participants completed a questionnaire on sociodemographics, comorbidity, medication and nutrition.

\section{Biochemistry}

Thyrotropin receptor antibody, thyrotropin, free triiodothyronine and thyroxine were measured by electrochemiluminescence immunoassays using the Cobas 6000 analyzer (Roche, Denmark). Total cholesterol, high-density lipoprotein and triglyceride were measured by absorption photometry using the Chemistry XPT, Siemens, Denmark.

\section{Statistics}

Sample size calculation was performed based on findings from a meta-analysis showing that risk of total and cardiovascular death increased by $15 \%$ for every increase of $1 \mathrm{~m} / \mathrm{s}$ in PWV [22]. Given a standard deviation of $1.5 \mathrm{~m} / \mathrm{s}, 36$ participants would be needed in each group to detect a difference of $1 \mathrm{~m} / \mathrm{s}$ with a statistical power of $80 \%$ at a $5 \%$ significance level. However, to allow for dropouts, we included 55 participants in each group.

The distribution of variables was assessed using QQ plots. According to the distribution of data, differences between groups were assessed using the Student's $t$ test or Wilcoxon rank-sum test for continuous variables. For categorical variables, we used the $\chi^{2}$ test or Fisher's exact test, as appropriate. Results are reported as mean \pm standard deviation or median with range or interquartile (25-75th percentile) range (IQR).

Using linear regression analysis, between-group differences of PWV were adjusted for age, sex, mean arterial pressure (office or $24 \mathrm{~h}$ as appropriate), heart rate (HR; office or $24 \mathrm{~h}$ as appropriate) and smoking. Analyses of BP were adjusted for age, sex, HR, smoking and BMI. Differences in Aix were adjusted for age, sex, HR, height and smoking.

Nightly dipping was calculated as (mean daytime - mean night-time)/mean daytime. Adjustments were performed as mentioned above, and the results are reported as the percentages difference in dipping among GD compared with controls.

All analyses were performed using STATA version 13.1 (STATA Corp LP, College Station, TX, USA).

\section{Results}

Participants' characteristics are shown in Table 1. Patients and the euthyroid controls were well matched. The two groups had comparable BMI and a similar proportion of current smokers. Furthermore, there were no statistical between-group differences in marital status, living form, educational level, employment, dietary habits or use of alcohol (data not shown). Cholesterol levels were lower in the group of patients (Table 1). Mean time since 
Table 1. Characteristics of participants

\begin{tabular}{lccc}
\hline & Euthyroid controls $(n=55)$ & Graves' disease $(n=55)$ & $p$ value \\
\hline Female, $n(\%)$ & $45(82)$ & $45(82)$ & 1.00 \\
Age, years & $40 \pm 14$ & $40 \pm 14$ & 0.97 \\
Height, cm & $170 \pm 9$ & $170 \pm 9$ & 0.73 \\
Weight, $\mathrm{kg}$ & $66.8(61.1$ to 79.1$)$ & $67.7(60.2$ to 83.4$)$ & 0.84 \\
BMI, $\mathrm{kg} / \mathrm{m}^{2}$ & $23.5(21.6$ to 25.8$)$ & $24.7(20.3$ to 27.3$)$ & 0.83 \\
Hypertension, $n(\%)^{\mathrm{a}}$ & $6(10.9)$ & $8(14.6)$ & 0.57 \\
Current smokers, $n(\%)$ & $6(10.9)$ & $9(16.4)$ & 0.41 \\
\hline Biochemistry & & & $<0.0001$ \\
Thyrotropin, IU/L & $2.2(1.5$ to 3.2$)$ & $0.0(0.0$ to 0.0$)$ & $<0.0001$ \\
Free triiodothyronine, pmol/L & $4.8(4.6$ to 5.1$)$ & $11.6(8.0$ to 15.8$)$ & $<0.0001$ \\
Free thyroxine, $\mathrm{pmol} / \mathrm{L}$ & $15.1(14.1$ to 16.6$)$ & $32.3(24.9$ to 41.9$)$ & $<0.0001$ \\
TRAb, IU/L & $<0.9$ & $9.3(4.8$ to 15.4$)$ & $<0.001$ \\
Cholesterol, mmol/L & $4.7 \pm 0.9$ & $4.1 \pm 0.8$ & $<0.001$ \\
LDL, mmol/L & $2.6 \pm 0.8$ & $2.1 \pm 0.7$ & $<0.05$ \\
HDL, mmol/L & $1.7 \pm 0.5$ & $1.5 \pm 0.5$ & $<0.001$ \\
Triglyceride, mmol/L & $0.8(0.6$ to 1.0$)$ & $1.0(0.8$ to 1.3$)$ & \\
\hline
\end{tabular}

Numbers $(n)$ with percentage $(\%)$, mean \pm standard deviation or median with interquartile range. ${ }^{\mathrm{a}}$ Hypertension diagnosed prior to enrollment. ${ }^{\mathrm{b}}$ Reference ranges: thyrotropin $0.3-4.5$; free triiodothyronine 3.9-6.8; free thyroxine 12-21; thyrotropin receptor antibody (TRAb) $<1.75$; total cholesterol $<5.0$; low-density lipoprotein (LDL) cholesterol <3.0; high-density lipoprotein (HDL) cholesterol $>1.2$ (women); triglyceride $<2.0$.

diagnosis was 16 (IQR: 9-24) days. At the time of investigation, $98 \%$ of the patients had initiated anti-thyroid treatment with a mean duration of 8 (IQR: 5-15) days. None of participants were diagnosed with ischemic heart disease, cerebrovascular disease, peripheral vascular disease, atrial fibrillation or type 2 diabetes mellitus.

Table 2 shows findings from office and 24 -h measurements of BP and indices of arterial stiffness. Compared with the controls, patients had a significantly higher heart rate, whereas systolic and diastolic BP did not differ in either brachial or central measurements. Among the subgroups with available 24-h PWV ( $n=88 ; 39$ GD and 49 controls), age, sex, height and BMI were comparable (data not shown).

Patients with GD had a significantly higher 24-h PWV, whereas office PWV did not differ between groups (Fig. 1). Patients with GD had significantly higher brachial PP both in office setting and during 24-h ambulatory measurements (Fig. 1). Night-time brachial and central PP dipping was significantly lower in the GD group (Table 2). Comparing office PWV within the control group according to achievement of 24-h PWV or not, we found no difference.

Results of the adjusted analysis are shown in Table 3. The estimated adjusted difference in $24-\mathrm{h}$ PWV was 1.0 (95\% confidence interval, CI: $0.6-1.5$ ) $\mathrm{m} / \mathrm{s}$ higher in the GD group, whereas PWV in the office setting did not dif- fer between groups. In both office and 24-h measurements, central and brachial PP measurements were significantly higher in patients compared to controls after adjustments. The between-group differences in 24-h central and brachial PP were of similar magnitude (Table 3 ). 24-h PWV was successful in a subgroup of participants ( $n=88 ; 39$ GD and 49 controls).

24-h central PP and 24-h PWV showed a significant positive linear correlation with an increase in 24-h PWV of 0.5 (95\% CI $0.3-0.6) \mathrm{m} / \mathrm{s}$ per every $5 \mathrm{~mm} \mathrm{Hg}$ increase in $24-\mathrm{h}$ central PP. When replacing $24-\mathrm{h}$ mean arterial pressure with 24-h central PP in the adjusted analysis of 24-h PWV, the association of higher 24-h PWV in the GD group was attenuated but remained significant (24-h PWV GD vs. controls: 0.8 (95\% CI: 0.3-1.3) m/s.

In 75 participants ( 34 patients and 41 controls), simultaneous measurements using the SphygmoCor Xcel and the Arteriograph were available. The adjusted difference in PWV obtained by the Arteriograph differed nonsignificantly between GD and controls $(0.6,95 \% \mathrm{CI}:-0.1$ to $1.2 \mathrm{~m} / \mathrm{s}$ ).

Thirty of 55 (55\%) participants in the GD group were prescribed beta-blocking drugs (BB) during ambulatory monitoring. As expected, patients prescribed $\mathrm{BB}$ had numerically, although nonsignificantly, higher levels of thyroid hormones. However, there were no differences in de- 
Table 2. Blood pressure and measures of arterial stiffness in patients newly diagnosed with Graves' disease (GD) compared to euthyroid controls

\begin{tabular}{|c|c|c|c|}
\hline & $\begin{array}{l}\text { Euthyroid controls } \\
(n=55)\end{array}$ & $\begin{array}{l}\mathrm{GD} \\
(n=55)\end{array}$ & $p$ value \\
\hline \multicolumn{4}{|l|}{ Office measurements } \\
\hline Heart rate, bpm & $59 \pm 8$ & $72 \pm 12$ & $<0.0001$ \\
\hline $\mathrm{PWV}, \mathrm{m} / \mathrm{s}^{\mathrm{a}}$ & $8.1(7.2$ to 8.9$)$ & $8.4(7.6$ to 8.2$)$ & 0.21 \\
\hline Aix, \% & $22.7 \pm 15.3$ & $23.7 \pm 15.0$ & 0.75 \\
\hline \multicolumn{4}{|l|}{ Brachial measurements } \\
\hline $\mathrm{SBP}, \mathrm{mm} \mathrm{Hg}$ & $120.2 \pm 12.6$ & $124.5 \pm 14.2$ & 0.10 \\
\hline $\mathrm{DBP}, \mathrm{mm} \mathrm{Hg}$ & $71.3 \pm 8.6$ & $71.3 \pm 9.2$ & 0.99 \\
\hline $\mathrm{PP}, \mathrm{mm} \mathrm{Hg}$ & $49.0 \pm 7.8$ & $53.2 \pm 9.1$ & 0.01 \\
\hline $\mathrm{MAP}, \mathrm{mm} \mathrm{Hg}$ & $87.6 \pm 9.4$ & $89.0 \pm 10.3$ & 0.45 \\
\hline \multicolumn{4}{|l|}{ Central measurements } \\
\hline $\mathrm{SBP}, \mathrm{mm} \mathrm{Hg}$ & $108.5 \pm 13.4$ & $110.4 \pm 14.4$ & 0.47 \\
\hline $\mathrm{DBP}, \mathrm{mm} \mathrm{Hg}$ & $71.6 \pm 8.4$ & $71.9 \pm 9.5$ & 0.85 \\
\hline $\mathrm{PP}, \mathrm{mm} \mathrm{Hg}$ & $36.5 \pm 7.3$ & $38.0 \pm 8.3$ & 0.30 \\
\hline MAP, $\mathrm{mm} \mathrm{Hg}$ & $85.3 \pm 9.9$ & $88.7 \pm 11.5$ & 0.10 \\
\hline \multicolumn{4}{|l|}{ 24-h measurements ${ }^{\mathrm{b}}$} \\
\hline Heart rate, bpm & $68 \pm 9$ & $81 \pm 10$ & $<0.0001$ \\
\hline $\mathrm{PWV}, \mathrm{m} / \mathrm{s}^{\mathrm{c}}$ & $7.6 \pm 1.0$ & $9.2 \pm 1.4$ & $<0.0001$ \\
\hline Aix, $\%^{c}$ & $23.1(14.7$ to 36.1$)$ & 18.1 (12.9 to 25.9$)$ & 0.13 \\
\hline \multicolumn{4}{|l|}{ Brachial measurements } \\
\hline $\mathrm{SBP}, \mathrm{mm} \mathrm{Hg}$ & $121.9 \pm 13.0$ & $124.8 \pm 12.8$ & 0.30 \\
\hline $\mathrm{DBP}, \mathrm{mm} \mathrm{Hg}$ & $70.0 \pm 8.5$ & $67.0 \pm 7.8$ & 0.10 \\
\hline $\mathrm{PP}, \mathrm{mm} \mathrm{Hg}$ & $52.0 \pm 8.1$ & $57.8 \pm 7.3$ & $<0.001$ \\
\hline MAP, $\mathrm{mm} \mathrm{Hg}$ & $87.4 \pm 9.5$ & $86.3 \pm 9.2$ & 0.59 \\
\hline \multicolumn{4}{|l|}{ Central measurements } \\
\hline $\mathrm{SBP}, \mathrm{mm} \mathrm{Hg}^{\mathrm{c}}$ & $112.6(106.5$ to 125.0$)$ & $111.8(106.3$ to 123.7$)$ & 0.97 \\
\hline $\mathrm{PP}, \mathrm{mm} \mathrm{Hg}$ & 44.3 (40.6 to 51.0$)$ & $46.5(43.5$ to 52.7$)$ & 0.14 \\
\hline $\mathrm{MAP}, \mathrm{mm} \mathrm{Hg}$ & $84.4 \pm 10.1$ & $83.5 \pm 10.3$ & 0.73 \\
\hline \multicolumn{4}{|l|}{ Nightly dipping } \\
\hline PWV dipping, $\%^{c}$ & $8.0 \pm 7.2$ & $4.0 \pm 9.9$ & 0.07 \\
\hline SBP dipping, \% & $12.3 \pm 7.0$ & $10.3 \pm 5.7$ & 0.15 \\
\hline DBP dipping, \% & $17.4 \pm 8.7$ & $17.2 \pm 8.7$ & 0.90 \\
\hline PP dipping, \% & $6.7(0.0$ to 11.9$)$ & $0(-3.1$ to 6.1$)$ & 0.02 \\
\hline Central SBP dipping, \% & $11.5 \pm 6.4$ & $9.3 \pm 7.4$ & 0.21 \\
\hline Central PP dipping, \% & $2.8 \pm 8.4$ & $-2.8 \pm 9.1$ & 0.01 \\
\hline
\end{tabular}

Mean \pm standard deviation or median with interquartile range. PWV, pulse wave velocity; Aix, augmentation index; SBP, systolic blood pressure; DBP, diastolic blood pressure; PP, pulse pressure; MAP, mean arterial blood

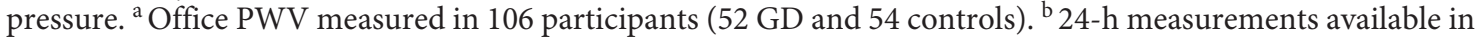
88 participants ( 39 GD and 49 controls). ${ }^{c} \mathrm{PWV}$ and AIX available in 65 participants ( $34 \mathrm{GD}$ and 31 controls).

mographics, or in the level of BP, PP or PWV between groups (data not shown).

\section{Circadian Variation}

We found that patients had higher PWV during both day and night. PP was only significantly higher during night-time, although estimates and CIs of the difference during daytime had similar direction (Table 4). When investigating differences in the day-night ratio, we found significantly lower nightly dipping of PWV and central PP among the patients (Table 4).

\section{Discussion}

The main purpose of our study was to compare arterial stiffness and $\mathrm{BP}$ in patients newly diagnosed with GD and matched controls. Our findings do not support dif- 


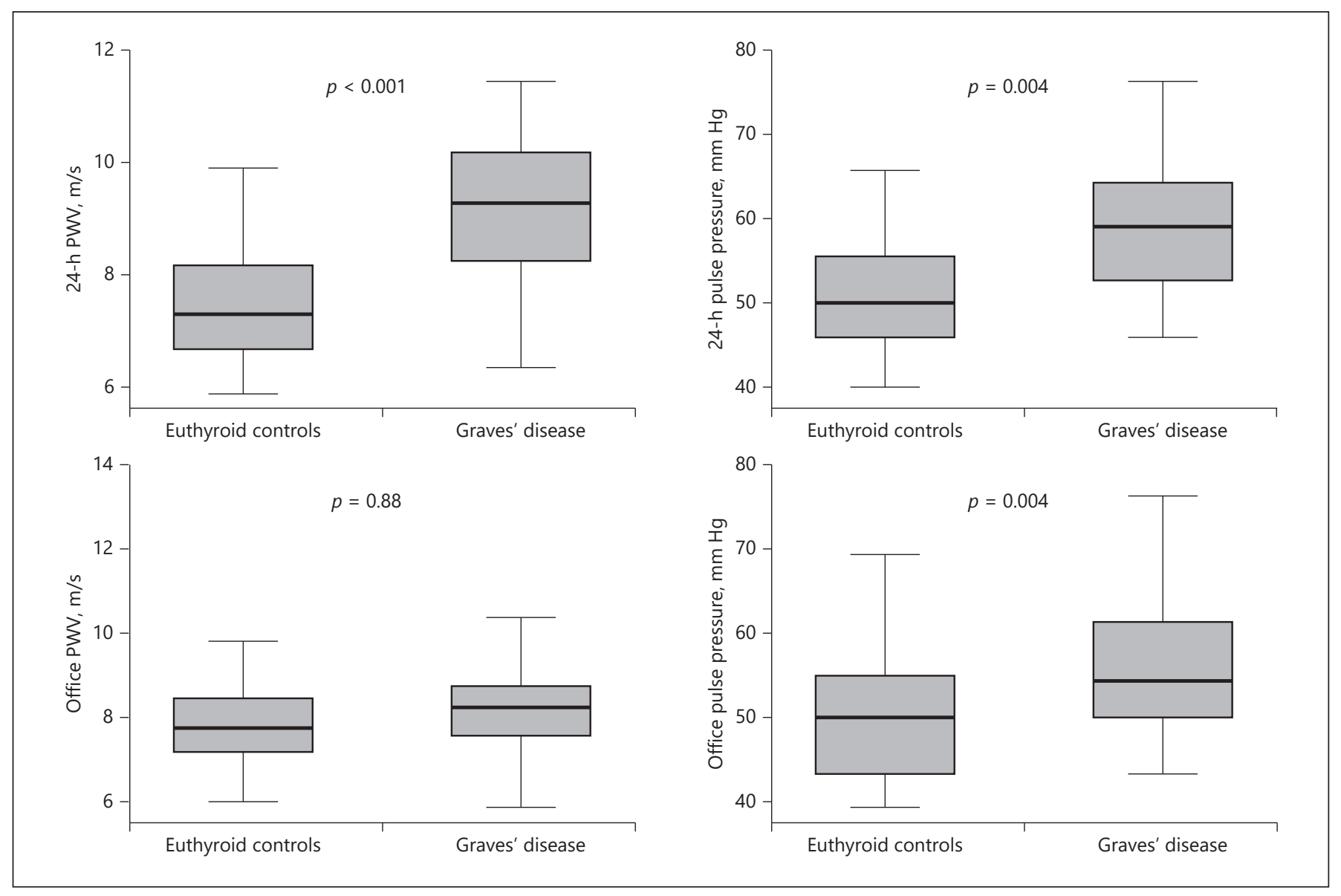

Fig. 1. Box-and-whisker plots of 24-h and office pulse wave velocity (PWV) and pulse pressure in patients with Graves' disease and euthyroid controls. The $p$ values refer to a multivariable linear regression analysis of the difference between groups, adjusted for age, sex, mean arterial pressure, heart rate and smoking (PWV), or age, sex, heart rate, smoking and body mass index (pulse pressure).

ferences in BP but did show a significantly higher 24-h carotid-femoral PWV in patients with GD compared with euthyroid controls. This difference in PWV was not detected in the office setting. In addition, GD was associated with a significantly higher brachial and central PP, as well as changes in the circadian pattern of arterial stiffness in terms of lower night-time PWV dipping and lower night-time central PP dipping.

The existing literature on arterial stiffness in hyperthyroid patients with GD is sparse and shows conflicting results. This may be due to the use of different measurement methods as well as due to reporting of different indices of arterial stiffness. Only a few studies included a control group for comparison. Two studies performed pulse wave analysis from radial tonometry estimating Aix from recordings of the wave reflection $[12,17]$, whereas 3 other studies assessed arterial stiffness using ultrasonic measurements of changes in large artery diameter [13-15].

Due to the different methodologies applied, a comparison to our results is not straightforward.

Simultaneous office PWV measurements using the SphygmoCor Xcel and the Arteriograph devices displayed no difference between groups, suggesting that office measurements are inadequate in detecting the increased PWV in patients with GD. The test of difference in office PWV between groups displayed a $p$ value close to 0.05 when PWV obtained using the Arteriograph was analyzed. Thus, it is possible that the different methodological approaches contribute to the diverging findings regarding PWV in the office and ambulatory setting. However, the larger amount of data obtained in 24 -h versus office monitoring, contributes to smaller variation in data and facili- 
Table 3. Adjusted analyses on differences in pulse wave velocity (PWV), blood pressure and augmentations index (Aix) in patients newly diagnosed with Graves' disease (GD) versus euthyroid controls (reference)

\begin{tabular}{|c|c|c|}
\hline GD vs. controls & $\begin{array}{l}\text { Mean difference between } \\
\text { groups }(95 \% \mathrm{CI})\end{array}$ & $p$ value \\
\hline \multicolumn{3}{|l|}{ Office measurements } \\
\hline $\mathrm{PWV}, \mathrm{m} / \mathrm{s}^{\mathrm{a}}$ & $-0.2(-0.6$ to 0.3$)$ & 0.49 \\
\hline Aix, $\%^{c}$ & $4.3(-0.6$ to 9.2$)$ & 0.09 \\
\hline \multicolumn{3}{|c|}{ Brachial measurements } \\
\hline $\mathrm{SBP}, \mathrm{mm} \mathrm{Hg}^{\mathrm{b}}$ & $2.8(-2.2$ to 7.8$)$ & 0.27 \\
\hline $\mathrm{DBP}, \mathrm{mm} \mathrm{Hg}^{\mathrm{b}}$ & $-1.6(-5.1$ to 2.0$)$ & 0.38 \\
\hline $\mathrm{PP}, \mathrm{mm} \mathrm{Hg}^{\mathrm{b}}$ & $4.3(1.1$ to 7.6$)$ & 0.01 \\
\hline MAP, $\mathrm{mm} \mathrm{Hg}^{\mathrm{b}}$ & $-0.1(-3.9$ to 3.6$)$ & 0.95 \\
\hline \multicolumn{3}{|c|}{ Central measurements } \\
\hline $\mathrm{SBP}, \mathrm{mm} \mathrm{Hg}^{\mathrm{b}}$ & $1.5(-3.2$ to 6.1$)$ & 0.54 \\
\hline $\mathrm{DBP}, \mathrm{mm} \mathrm{Hg}^{\mathrm{b}}$ & $-1.7(-5.2$ to 1.9$)$ & 0.36 \\
\hline $\mathrm{PP}, \mathrm{mm} \mathrm{Hg}^{\mathrm{b}}$ & $3.1(0.5$ to 5.8$)$ & 0.02 \\
\hline MAP, $\mathrm{mm} \mathrm{Hg}^{\mathrm{b}}$ & $0.3(-3.7$ to 4.2$)$ & 0.90 \\
\hline \multicolumn{3}{|l|}{ 24-h measurements } \\
\hline $\mathrm{PWV}, \mathrm{m} / \mathrm{s}^{\mathrm{a}}$ & $1.0(0.6$ to 1.5$)$ & $<0.001$ \\
\hline $\mathrm{Aix}, \%^{\mathrm{c}}$ & $-1.3(-4.9$ to 2.2$)$ & 0.46 \\
\hline \multicolumn{3}{|c|}{ Brachial measurements } \\
\hline $\mathrm{SBP}, \mathrm{mm} \mathrm{Hg}^{\mathrm{b}}$ & $1.6(-4.5$ to 7.7$)$ & 0.60 \\
\hline DBP, $\mathrm{mm} \mathrm{Hg}^{\mathrm{b}}$ & $-3.0(-7.0$ to 1.0$)$ & 0.14 \\
\hline $\mathrm{PP}, \mathrm{mm} \mathrm{Hg}^{\mathrm{b}}$ & $4.6(0.8$ to 8.4$)$ & 0.02 \\
\hline $\mathrm{MAP}, \mathrm{mm} \mathrm{Hg}$ & $-1.5(-6.0$ to 3.0$)$ & 0.51 \\
\hline \multicolumn{3}{|c|}{ Central measurements } \\
\hline $\mathrm{SBP}, \mathrm{mm} \mathrm{Hg}^{\mathrm{b}}$ & $1.1(-6.3$ to 8.5$)$ & 0.77 \\
\hline $\mathrm{PP}, \mathrm{mm} \mathrm{Hg}^{\mathrm{b}}$ & $4.8(0.7$ to 8.9$)$ & 0.02 \\
\hline MAP, mm Hg & $-2.1(-7.4$ to 3.2$)$ & 0.43 \\
\hline
\end{tabular}

SBP, systolic blood pressure; DBP, diastolic blood pressure; MAP, mean arterial blood pressure; PP, pulse pressure; Aix, augmentation index. ${ }^{a}$ Adjusted for age, sex, heart rate (office or $24 \mathrm{~h}$ ), MAP and smoking. ${ }^{\mathrm{b}}$ Adjusted for age, sex, body mass index, heart rate (office or $24 \mathrm{~h}$ ) and smoking. ${ }^{\mathrm{c}}$ Adjusted for age, sex, heart rate (office or $24 \mathrm{~h}$ ), height and smoking.

tates detection of differences between groups. Furthermore, the consistent observation of increased PP in the GD group is in agreement with the higher PWV.

In contrast to our findings, a number of other studies have reported a higher systolic BP in GD compared with controls [23-25], whereas other studies found similar results $[17,26]$. Differences in disease severity at the time of investigation might contribute to the diverging finding. Thus, in one study, BP measurements in the patient group were performed before and after 14 days of anti-thyroid treatment, and at this later time point the initial difference in systolic BP compared with controls disappeared
Table 4. Adjusted analyses of differences in nightly dipping and day- and night-time blood pressure, pulse wave velocity and wave reflection in patients newly diagnosed with Graves' disease (GD) compared to euthyroid controls (reference)

\begin{tabular}{|c|c|c|}
\hline GD vs. controls & $\begin{array}{l}\text { Difference between } \\
\text { groups }(95 \% \mathrm{CI})\end{array}$ & $p$ value \\
\hline \multicolumn{3}{|l|}{ Daytime } \\
\hline $\mathrm{PWV}, \mathrm{m} / \mathrm{s}^{\mathrm{a}}$ & $1.0(0.5$ to 1.4$)$ & $<0.001$ \\
\hline $\mathrm{PP}, \mathrm{mm} \mathrm{Hg}^{\mathrm{b}}$ & $3.8(-0.0$ to 7.6$)$ & 0.05 \\
\hline $\mathrm{SBP}, \mathrm{mm} \mathrm{Hg}$ & $0.5(-5.9$ to 6.8$)$ & 0.88 \\
\hline $\mathrm{DBP}, \mathrm{mm} \mathrm{Hg}^{\mathrm{b}}$ & $-3.3(-7.6$ to 1.0$)$ & 0.13 \\
\hline Aix, $\%^{c}$ & $-2.3(-5.7$ to 1.1$)$ & 0.19 \\
\hline Central PP, mm Hg ${ }^{\mathrm{b}}$ & $3.3(-0.8$ to 7.4$)$ & 0.12 \\
\hline \multicolumn{3}{|l|}{ Night-time } \\
\hline $\mathrm{PWV}, \mathrm{m} / \mathrm{s}^{\mathrm{a}}$ & $1.2(0.7$ to 1.8$)$ & $<0.001$ \\
\hline $\mathrm{PP}, \mathrm{mm} \mathrm{Hg}{ }^{\mathrm{b}}$ & $5.5(1.5$ to 9.4$)$ & $<0.01$ \\
\hline SBP mm Hg ${ }^{b}$ & $4.1(-2.4$ to 10.6$)$ & 0.21 \\
\hline $\mathrm{DBP}^{\mathrm{b}}, \mathrm{mm} \mathrm{Hg}^{\mathrm{b}}$ & $-1.3(-5.6$ to 2.9$)$ & 0.53 \\
\hline Aix, $\%^{c}$ & $1.2(-3.2$ to 5.5$)$ & 0.59 \\
\hline Central PP, $\mathrm{mm} \mathrm{Hg}^{\mathrm{b}}$ & $6.9(2.6$ to 11.3$)$ & $<0.01$ \\
\hline \multicolumn{3}{|l|}{ Night-time dipping } \\
\hline PWV,$\% \mathrm{~d}^{\mathrm{d} P}$ & $-5.5(-10.4$ to 0.6$)$ & 0.03 \\
\hline $\mathrm{HR}, \%^{\mathrm{e}}$ & $-3.4(0.1$ to 6.8$)$ & 0.04 \\
\hline SBP, $\%^{\mathrm{f}}$ & $-1.9(-5.4$ to 1.5$)$ & 0.27 \\
\hline DBP, $\%^{\mathrm{f}}$ & $-1.8(-6.4$ to 2.7$)$ & 0.43 \\
\hline$P P, \%^{f}$ & $-0.5(-4.6$ to 3.6$)$ & 0.82 \\
\hline Central SBP, $\%{ }^{\mathrm{f}}$ & $-3.5(-7.7$ to 0.6$)$ & 0.09 \\
\hline Central PP, $\%^{\mathrm{f}}$ & $-5.4(-10.5$ to 0.2$)$ & 0.04 \\
\hline
\end{tabular}

PWV, pulse wave velocity; SBP, brachial systolic blood pressure; MAP, brachial mean arterial blood pressure; PP, brachial pulse pressure; Aix, augmentation index; HR, heart rate. ${ }^{\text {a }}$ Adjusted for age, sex, heart rate (office or $24 \mathrm{~h}$ ), MAP and smoking. ${ }^{\mathrm{b}}$ Adjusted for age, sex, heart rate (office or $24 \mathrm{~h}$ ), BMI and smoking. ${ }^{\text {c Adjusted }}$ for age, sex, heart rate (office or $24 \mathrm{~h}$ ), height and smoking. ${ }^{\mathrm{d}}$ Adjusted for age, sex, and night-time mean heart rate, MAP and smoking. ${ }^{\mathrm{e}}$ Adjusted for age and sex. ${ }^{\mathrm{f}}$ Adjusted for age, sex, mean night-time heart rate, BMI and smoking.

[25]. This finding suggests a reversible component of the changes in BP caused by hyperthyroidism.

In line with a study by Obuobie et al. [17], we found higher central and brachial PP in patients with GD. To some extent, the higher PWV might be attributed the higher PP, and a correlation between PWV and PP was demonstrated. However, the correlation may also reflect a shared dependence on other hemodynamic changes such as increased stroke volume, caused by the increased cardiac contractility in hyperthyroidism [27].

Excess thyroid hormones induce a hyperkinetic circulation with increased $\mathrm{HR}$, reduced peripheral vascular re- 
sistance, increased blood volume and increased cardiac output [28-30]. However, knowledge on the effect of hyperthyroidism on the large elastic arteries is sparse. The main determinant of the mechanical properties of the aorta is the arterial wall composition of elastin and collagen fibers: at higher strain the elasticity is reduced [31]. Thus, the hypervolemic circulation in hyperthyroidism with increased aorta filling potentially adds to the central arterial stiffness.

The 24-h measurements revealed an adverse diurnal profile presumably adding to the cardiovascular burden of hyperthyroidism. As HR is positively associated with PWV, the disturbed circadian HR rhythm might contribute to the unfavorable lower PWV and PP dipping. Thus, repeated pulsations have been associated with adverse cumulative effects on viscoelastic properties of the aortic wall in terms of impaired structural integrity of the elastic component. The increased arterial stiffness might also have a structural component. Thus, studies on hyperthyroid rats have shown changes in vessel wall composition of collagen and elastin [32]. These findings suggest that the increased arterial stiffness might not merely reflect functional adaptation to altered hemodynamics. The repeated shear-stress on arterial wall caused by the hyperkinetic circulation in hyperthyroidism might be of importance. An assessment of carotid intima-media thickness might help to distinguish a structural component of the higher arterial stiffness suggestive of a lasting condition.

The effect size of the observed PWV difference in the present study is of clinical significance as an increase in PWV of $1 \mathrm{~m} / \mathrm{s}$ translates to a $15 \%$ increase in cardiovascular morbidity [22]. Longitudinal data are needed to explore the possible transitory nature of this PWV elevation. If enduring, however, the higher PWV might contribute to the excess CVD in GD.

\section{Strengths and Limitations}

This study has a large sample size and a well-matched population-based control group. Weight and BMI were not lower in the patients compared with the controls. Nordyke et al. [33] observed weight loss to be less pronounced with younger age of GD patients coinciding with increased appetite. Thus, the relatively young age of the patients might contribute to the lack of any weight difference between groups.

PWV was performed using the gold standard method under standardized conditions. Additionally, we performed 24-h PWV measurements to gain novel knowledge on diurnal variation in arterial stiffness and the cardiovascular burden in hyperthyroidism.
Incomplete data collection regarding 24-h monitoring is a limitation to our study as 16 of the patients (due to lack of devices) and 6 of the controls (due to refusal) never had this measurement performed. Furthermore, the ambulatory PWV measurement failed in 5 of the patients and 18 of the controls. However, the subgroups achieving 24-h PWV were comparable, and we demonstrated that the level of arterial stiffness did not affect success of achievement of 24-h PWV.

A key limitation to the interpretation of our data is the lack of longitudinal data after correction of hyperthyroidism to establish whether the higher level of PWV in GD is temporary; A persistently higher level of PWV in euthyroid GD patients would emphasize the clinical implications of the observed association.

\section{Conclusions}

To the best of our knowledge, this is the first study to assess arterial stiffness in hyperthyroid patients with GD by means of carotid-femoral PWV, recommended as the gold standard method of estimating arterial stiffness. This is also the first study to describe 24-h measurements of PWV in patients with GD. Our study revealed increased 24-h PWV that was undetectable in the office setting in patients with GD, suggesting that office measurements are not appropriate in recognizing possible unfavorable cardiovascular effects of hyperthyroidism. Increased brachial and central PP support the notion of increased arterial stiffness in GD. Further studies on the effect of restoration of euthyroidism on PWV are needed to explore whether the observed higher level of PWV reflects transient physiologic adaptations to the hyperkinetic circulation in hyperthyroidism or persistent vascular damage. Increased PWV may offer a piece to the puzzle of understanding increased CVD risk in hyperthyroidism and GD.

\section{Statement of Ethics}

The study was performed in accordance with the World Medical Association Declaration of Helsinki. All participants gave written informed consent. The Regional Committee on Biomedical Research Ethics approved the study.

\section{Disclosure Statement}

The authors have no conflicts of interest to declare. 


\section{Funding Sources}

This work was supported by the Novo Nordic Foundation (NNF15OC0017792) and Toyotafonden Denmark. Funders had no role in design of the study, nor in collection, interpretation or reporting of data.

\section{Author Contributions}

Diana Grove-Laugesen: study conception/design, data acquisition, analysis and interpretation of data; writing of first draft; critical revision and final approval of the manuscript. Sofie
Malmstroem: data acquisition, data interpretation, critical revision and final approval of the manuscript. Eva Ebbehoj: data interpretation, critical revision and final approval of the manuscript. Anne Lene Riis: data interpretation, critical revision and final approval of the manuscript. Torquil Watt: data interpretation, critical revision and final approval of the manuscript. Lars Rejnmark: study conception/design, data analysis and interpretation; critical revision and final approval of the manuscript. Klavs Würgler Hansen: study conception/design, data interpretation; critical revision and final approval of the manuscript.

\section{References}

1 Brandt F, Green A, Hegedüs L, Brix TH. A critical review and meta-analysis of the association between overt hyperthyroidism and mortality. Eur J Endocrinol. 2011 Oct;165(4): 491-7.

2 Dekkers OM, Horváth-Puhó E, Cannegieter SC, Vandenbroucke JP, Sørensen HT, Jørgensen JO. Acute cardiovascular events and all-cause mortality in patients with hyperthyroidism: a population-based cohort study. Eur J Endocrinol. 2017 Jan;176(1):1-9.

3 Franklyn JA, Maisonneuve P, Sheppard MC, Betteridge J, Boyle P. Mortality after the treatment of hyperthyroidism with radioactive iodine. N Engl J Med. 1998 Mar;338(11):712-8.

4 Hall P, Lundell G, Holm LE. Mortality in patients treated for hyperthyroidism with iodine-131. Acta Endocrinol (Copenh). 1993 Mar;128(3):230-4. [cited 2019 Feb 19].

5 Okosieme OE, Taylor PN, Evans C, Thayer D, Chai A, Khan I, et al. Primary therapy of Graves' disease and cardiovascular morbidity and mortality: a linked-record cohort study. Lancet Diabetes Endocrinol. 2019 Apr;7(4): 278-87.

6 Hansen TW, Jeppesen J, Rasmussen S, Ibsen $\mathrm{H}$, Torp-Pedersen C. Ambulatory blood pressure monitoring and risk of cardiovascular disease: a population based study. Am J Hypertens. 2006 Mar;19(3):243-50.

7 Shoji T, Emoto M, Shinohara K, Kakiya R, Tsujimoto Y, Kishimoto H, et al. Diabetes mellitus, aortic stiffness, and cardiovascular mortality in end-stage renal disease. J Am Soc Nephrol. 2001 Oct;12(10):2117-24. [cited 2018 Nov 6].

8 Mattace-Raso FU, van der Cammen TJ, Hofman A, van Popele NM, Bos ML, Schalekamp $\mathrm{MA}$, et al. Arterial stiffness and risk of coronary heart disease and stroke: the Rotterdam Study. Circulation. 2006 Feb;113(5):657-63.
9 Lewington S, Clarke R, Qizilbash N, Peto R, Collins R; Prospective Studies Collaboration. Age-specific relevance of usual blood pressure to vascular mortality: a meta-analysis of individual data for one million adults in 61 prospective studies. Lancet. 2002 Dec; 360(9349): 1903-13.

10 Laurent S, Cockcroft J, Van Bortel L, Boutouyrie P, Giannattasio C, Hayoz D, et al.; European Network for Non-invasive Investigation of Large Arteries. Expert consensus document on arterial stiffness: methodological issues and clinical applications. Eur Heart J. 2006 Nov;27(21):2588-605.

11 Akcay M, Akcay E, Yeter E, Durmaz T, Keles T, Bayram NA, et al. Aortic elastic properties are impaired in patients with Graves' ophtalmopathy. Vasa. 2011 Jan;40(1):41-8.

12 Bodlaj G, Pichler R, Brandstätter W, HatzlGriesenhofer M, Maschek W, Biesenbach G, et al. Hyperthyroidism affects arterial stiffness, plasma NT-pro-B-type natriuretic peptide levels, and subendocardial perfusion in patients with Graves' disease. Ann Med. 2007; 39(8):608-16.

13 Inaba M, Henmi Y, Kumeda Y, Ueda M, Nagata $\mathrm{M}$, Emoto $\mathrm{M}$, et al. Increased stiffness in common carotid artery in hyperthyroid Graves' disease patients. Biomed Pharmacother. 2002 Jul;56(5):241-6.

14 Czarkowski M, Hilgertner L, Powałowski T, Radomski D. The stiffness of the common carotid artery in patients with Graves' disease. Int Angiol. 2002 Jun;21(2):152-7.

15 Czarkowski M, Hilgertner L, Powałowski T, Radomski D, Mikulska M. Is the resistance of large conduit arteries also decreased in thyrotoxic patients with Graves' disease? Thyroid. 2005 Apr;15(4):377-81.

16 Shargorodsky M, Serov S, Gavish D, Leibovitz E, Harpaz D, Zimlichman R. Long-term thyrotropin-suppressive therapy with levothyroxine impairs small and large artery elasticity and increases left ventricular mass in patients with thyroid carcinoma. Thyroid. 2006 Apr;16(4):381-6.
17 Obuobie K, Smith J, John R, Davies JS, Lazarus $\mathrm{JH}$. The effects of thyrotoxicosis and its treatment on central arterial stiffness. Eur J Endocrinol. 2002 Jul;147(1):35-40.

18 Grove-Laugesen D, Malmstroem S, Ebbehoj E, Riis AL, Watt T, Hansen KW, et al. Effect of 9 months of vitamin D supplementation on arterial stiffness and blood pressure in Graves' disease: a randomized clinical trial. Endocrine. 2019 Nov;66(2):386-97.

19 Malmstroem S, Grove-Laugesen D, Riis AL, Bruun BJ, Ebbehoj E, Hansen KW, et al. Muscle Performance and Postural Stability Are Reduced in Patients with Newly Diagnosed Graves' Disease. Thyroid. 2019 Jun;29(6): 783-9.

20 Hwang MH, Yoo JK, Kim HK, Hwang CL, Mackay K, Hemstreet O, et al. Validity and reliability of aortic pulse wave velocity and augmentation index determined by the new cuff-based SphygmoCor Xcel. J Hum Hypertens. 2014 Aug;28(8):475-81.

21 Baulmann J, Schillings U, Rickert S, Uen S, Düsing R, Illyes M, et al. A new oscillometric method for assessment of arterial stiffness: comparison with tonometric and piezo-electronic methods. J Hypertens. 2008 Mar;26(3): 523-8.

22 Vlachopoulos C, Aznaouridis K, Stefanadis C. Prediction of cardiovascular events and allcause mortality with arterial stiffness: a systematic review and meta-analysis. J Am Coll Cardiol. 2010 Mar;55(13):1318-27.

23 Iglesias P, Acosta M, Sánchez R, FernándezReyes MJ, Mon C, Díez JJ. Ambulatory blood pressure monitoring in patients with hyperthyroidism before and after control of thyroid function. Clin Endocrinol (Oxf). 2005 Jul; 63(1):66-72.

24 Turhan İyidir Ö, Yalçın MM, Eroğlu Altınova A, Arslan E, Uncu B, Konca Değertekin C, et al. Evaluation of ambulatory arterial stiffness index in hyperthyroidism. Turk J Med Sci. 2017 Dec;47(6):1751-6. 
25 Marcisz C, Jonderko G, Kucharz E. Changes of arterial pressure in patients with hyperthyroidism during therapy. Med Sci Monit. 2002 Jul;8(7):CR502-7.

26 Aroditis K, Pikilidou M, Vourvouri E, Hadjistavri L, Zebekakis P, Yovos J, et al. Changes in cardiac function and structure in newly diagnosed Graves' disease. A conventional and 2D-speckle tracking echocardiography study. Int J Cardiovasc Imaging. 2017 Feb;33(2): 187-95.

27 Feldman T, Borow KM, Sarne DH, Neumann A, Lang RM. Myocardial mechanics in hyperthyroidism: importance of left ventricular loading conditions, heart rate and contractile state. J Am Coll Cardiol. 1986 May;7(5):96774.
28 Owen PJ, Sabit R, Lazarus JH. Thyroid disease and vascular function. Thyroid. 2007 Jun; 17(6):519-24

29 Klein I, Ojamaa K. Thyroid hormone and the cardiovascular system. N Engl J Med. 2001 Feb;344(7):501-9.

30 Biondi B, Palmieri EA, Lombardi G, Fazio S. Effects of thyroid hormone on cardiac function: the relative importance of heart rate, loading conditions, and myocardial contractility in the regulation of cardiac performance in human hyperthyroidism. J Clin Endocrinol Metab. 2002 Mar;87(3):968-74.
31 Nichols WW, O'Rourke MF, Vlachopoulos C, McDonald DA. McDonald's Blood Flow in Arteries: Theoretical, Experimental and Clinical Principles. 6th ed. Boca Raton: CRC Press; 2011.

32 Moulakakis KG, Sokolis DP, Perrea DN, Dosios T, Dontas I, Poulakou MV, et al. The mechanical performance and histomorphological structure of the descending aorta in hyperthyroidism. Angiology. 2007 Jun-Jul;58(3): 343-52.

33 Nordyke RA, Gilbert FI Jr, Harada AS. Graves' disease. Influence of age on clinical findings. Arch Intern Med. 1988 Mar;148(3):626-31. 